\title{
PROGRAM PENGEMBANGAN DESA MITRA: PENYEDIAAN OBAT HERBAL BAGI MASYARAKAT MELALUI USAHA KONSERVASI TUMBUHAN OBAT DI HALAMAN PEKARANGAN
}

\author{
Rosmini $^{1 x}$, Andi Ete ${ }^{1}$, Nur Edy ${ }^{1}$, Mohammad Yunus ${ }^{1}$, Sri Anjar Lasmini ${ }^{1}$, Flora Pasaru ${ }^{1}$, Dwi \\ Rohma Wulandari ${ }^{2}$, Sisi Pratiwi ${ }^{3}$, Riskayanti ${ }^{3}$ \\ ${ }^{1)}$ Program Studi Agroteknologi Fakultas Pertanian Universitas Tadulako \\ ${ }^{2)}$ Program Studi Komunikasi Fakultas Ilmu Sosial dan Ilmu Politik Universitas Tadulako \\ ${ }^{3)}$ Mahasiswa Program Studi Agroteknologi Fakultas Pertanian Universitas Tadulako
}

email: rhosmini.rosmini@gmail.com; andiete@gmail.com; nuredy01@gmail.com; mohyunus125@gmail.com; lasminisrianjar@gmail.com, pasaruhhpt@gmail.com

\begin{abstract}
Abstrak
Potensi keanekaragaman tumbuhan liar yang bermanfaat sebagai obat-obatan masih banyak diabaikan oleh masyarakat. Permasalahan ini terjadi antara lain karena pengetahuan yang dimiliki masyarakat masih tergolong rendah. Program pengembangan desa mitra bertujuan untuk meningkatkan pertisipasi masyarakat dalam mendukung tercapainya pusat konservasi tumbuhan obat (TO) di Sulawesi Tengah. Metode yang diterapkan adalah community development atau pengembangan masyarakat dengan langkah-langkah operasional adalah pembentukan kebun konservasi dan klinik tumbuhan obat dengan sasaran mengusahakan sebanyak mungkin tumbuhan yang berpotensi sebagai tumbuhan obat tradisional sebagai sumber plasma nutfa agar tidak punah dan menjadi sumber informasi. Hasil pelaksanaan pelatihan teknik konservasi tumbuhan obat untuk mendukung progam penyediaan obat herbal di Sulawesi Tengah kepada masyarakat di Desa Pakuli Kecamatan Gumbasa berlangsung dengan baik dan dapat diadopsi oleh masyarakat yang diindikasikan dengan kegiatan penanaman tumbuhan obat oleh masyarakat di halaman pekarangan rumah masing-masing. Pelaksanaan penyuluhan yang diikuti sebanyak 35 orang peserta dari 2 kelompok mitra dapat meningkatkan pengetahuan masyarakat yang ditandai dengan meningkatnya ketrampilan pada saat praktek budidaya tumbuhan obat, baik yang dilaksanakan di areal konservasi maupun di lahan pekarangan. Dengan konservasi tumbuhan obat terutama yang tergolong langka, maka masyarakat dapat mendekatkan diri dengan tumbuhan obat langka tersebut untuk kepentingan penyediaan obat herbal bagi anggota keluarganya.
\end{abstract}

Kata Kunci : Konservasi; tumbuhan; obat herbal

\section{PENDAHULUAN}

Obat herbal merupakan kelompok obat tradisional berupa campuran yang berasal dari tumbuh-tumbuhan, baik berupa jamu, obat herbal terstandar maupun fitofarmaka. Bila tumbuhan yang dikonsumsi masyarakat terbukti mampu menyembuhkan suatu macam penyakit mengakibatkan permintaan terhadap tumbuhan obat tersebut menjadi tinggi, sehingga berdampak pada 
nilai ekonomi dari spesies tumbuhan obat (TO) tersebut (Parwata, 2016).

Kebanyakan tumbuhan obat yang diperoleh masyarakat hidupnya di kawasan hutan, yakni tidak kurang $82 \%$ dari total spesies tumbuhan obat, hidup di ekosistem hutan tropika dataran rendah yang saat ini paling banyak rusak dan punah karena berbagai kegiatan manusia baik secara legal maupun tak legal (Zuhud, 2015). Kerusakan habitat merupakan faktor yang cukup signifikan mengancam kelestarian tumbuhan obat. Rusaknya habitat akan menyebabkan terganggunya pertumbuhan jenis-jenis tumbuhan obat tersebut. Bahkan kerusakan habitat dapat secara langsung menyebabkan kemusnahan. Habitat spesies tumbuhan obat perlu diperhatikan mengingat peran tumbuhan obat tersebut sangat penting dalam kehidupan manusia (Irwanta et al., 2015). Dengan demikian perlu pelestarian tumbuhan obat dengan melakukan konservasi tumbuhan obat khususnya yang tergolong langka dan bernilai ekonomi agar mudah diperoleh pada saat diperlukan dan tidak mengalami kelangkaan.

Konservasi tumbuhan obat hutan dapat dilakukan secara in-situ dan ex-situ. Konservasi insitu dilakukan dengan cara mengelola secara baik kawasan-kawasan hutan yang merupakan habitat asli dari tumbuhan obat yang bersangkutan, sedangkan konservasi tumbuhan obat secara ex-situ merupakan kegiatan perlindungan yang dilakukan diluar habitat asli dari suatu janis tumbuhan atau satwa (Noorhidayah et al., 2006). Konservasi exsitu juga dapat dikatakan sebagai tindakan domestikasi tumbuhan sehingga pada akhirnya dapat dibudidayakan secara luas.

Dengan adanya kegiatan budidaya tumbuhan obat secara tidak langsung dapat membantu mengurangi pengambilan jenis tersebut di alam liar. Selain itu, pembuatan kebun TOGA (tanaman obat keluarga) di lahan pekarangan setiap rumah dapat menjadi pilihan alternatif dalam upaya mempertahankan kelestarian tumbuhan obat dan tentunya merupakan sebuah aksi konservasi.

Budidaya tanaman didefinisikan sebagai segala usaha manusia yang diterapkan pada suatu kegiatan penanaman tanaman yang diharapkan akan diperoleh hasil yang lebih baik bila dibandingkan tanpa usaha budidaya. Dengan demikian budidaya tanaman obat dimaksudkan untuk menghasilkan simplisia yang berkualitas dalam menyediakan obat herbal bagi masyarakat.

Desa Pakuli Kecamatan Gumbasa terletak di bagian barat kawasan Taman Nasional Lore Lindu (TNLL) dikenal oleh masyarakat Kota Palu sebagai desa "Sando" yang dalam Bahasa Indonesia dimaknai sebagai desa tempat pengobatan tradisional. Nama Pakuli dalam bahasa lokal daerah Palu (Suku Kaili berarti "Obat"), menunjukkan bahwa Desa Pakuli memang sejak dahulu dikenal sebagai pusat pengobatan alternatif berupa penggunaan tumbuhan obat bila ada anggota masyarakat yang menderita sesuatu penyakit atau sesuatu yang berhubungan dengan masalah kesehatan.

Desa Pakuli yang berjarak sekitar $50 \mathrm{~km}$ ke arah selatan dari dari kota Palu (BPS Kabupaten Sigi, 2017), mudah dijangkau dengan berkendaraan roda dua ataupun roda empat, menjadikan daerah tersebut sebagai tempat pengobatan tradisional oleh masyarakat perkotaan di Palu Sulawesi Tengah, terutama meningkatnya trend gaya hidup kembali ke alam. Hal tersebut karena di Desa Pakuli terdapat barbagai jenis tumbuhan obat yang diyakini dapat menyembuhkan penyakit yang susah diperoleh di tempat lain. Selain itu juga dimaksudkan untuk berwisata di area konservasi tumbuhan obat yang dimiliki oleh salah seorang tokoh masyarakat yaitu H. Sahlan (kelompok pembudidaya tumbuhan obat Asyifa'a) yang sejak lama telah mengembangkan tumbuhan obat di area konservasi miliknya.

Meskipun dikenal sebagai desa konservasi tumbuhan obat, namun sampai saat ini potensi keanekaragaman tumbuhan obat masih banyak diabaikan dan belum dimanfaatkan. Di area konservasi pembudidaya tumbuhan obat Asyifa'a baru terdapat 30 jenis yang dikonservasi (Rosmini et al., 2020). Hal ini terjadi antara lain karena pengetahuan dan teknologi yang rendah yang dimiliki masyarakat, sehingga permasalahan ini perlu diatasi melalui suatu kegiatan revitalisasi konservasi tumbuhan obat. Hikmat et al. (2011) menyatakan bahwa dengan revitalisasi tumbuhan 
obat akan dapat meningkatkan kesehatan dan ekonomi keluarga masyarakat secara mandiri.

Dengan konservasi tumbuhan obat di halaman pekarangan terutama yang tergolong langka, maka masyarakat dapat mendekatkan diri dengan tumbuhan obat langka tersebut untuk kepentingan penyediaan obat herbal bagi anggota keluarganya (Rosmini et al., 2021).

Pogram pengabdian pengembangan desa mitra (PPDM) bertujuan untuk mendampingi masyarakat dalam penyediaan obat herbal melalui usaha konservasi tumbuhan obat di halaman pekarangan, dalam mendukung terciptanya Desa Pakuli sebagai pusat konservasi tumbuhan obat di Sulawesi Tengah berbasis agroforestri, konservasi dan ekowisata.

\section{METODE}

Metode yang dilakukan pada kegiatan program pengembangan desa mitra (PPDM) adalah: sosialisasi dan peninjauan areal konservasi milik kelompok pembudidaya tumbuhan obat Asyifa'a, penyuluhan, ceramah, diskusi, demonstrasi praktik langsung (demplot) budidaya tanaman obat, bimbingan dan pendampingan teknis. Penyuluhan disampaikan dengan cara klasikal yaitu peserta disatukan pada satu tempat kemudian diberikan materi tentang pentingnya tumbuhan obat dan upaya pelestariannya serta teknik budidaya tumbuhan obat. Selesai penyajian materi dilanjutkan dengan diskusi (Dewi dan Widiyawati, 2019).

Demonstrasi praktik langsung (demplot) meliputi tahapan persiapan media tanam, penanaman, dan pemeliharaan tanaman obat yang dilaksanakan di areal konservasi milik kelompok pembudidaya tumbuhan obat Asyifa'a dan di lahan pekarangan. Pelatihan teknik budidaya tumbuhan obat disesuaikan dengan persyaratan budidaya masing-masing tumbuhan obat yang akan diusahakan yang sesuai dengan Good Agricultural Practices (Sebayang et al. 2020). Bimbingan dan pendampingan teknis dilakukan selama tiga bulan sebagai rangkaian seluruh pelaksanaan program pengabdian skema program pengembangan desa mitra (PPDM).

\section{HASIL DAN PEMBAHASAN}

\subsection{Sosialisasi dan peninjauan kebun konservasi}

Sosialisasi dilaksanakan di balai pertemuan kelompok pembudidaya tumbuhan obat Asyifa'a Desa Pakuli Kecamatan Gumbasa yang dihadiri oleh seluruh anggota kelompok pembudidaya dan anggota masyarakat Desa Pakuli. Sosialisasi dilaksanakan untuk menyampaikan maksud, tujuan dan sasaran kegiatan PPDM serta membuat kesepakatan awal untuk rencana tindaklanjut yang akan diimplementasikan di lapangan. Materi sosialisasi meliputi pentingnya penggunaan tumbuhan obat sebagai alternatif pengobatan terutama di daerah yang masih jauh dari sarana kesehatan, teknik budidaya berbagai jenis tumbuhan obat, dan usaha konservasi tumbuhan obat.

Setelah pelaksanaan sosialisasi selanjutnya dilakukan penyerahan peralatan secara simbolis yang akan digunakan selama pelaksanaan program serta peninjauan ke kebun yang akan dipusatkan untuk pelaksanaan konservasi. Suasana kunjungan ke kebun konservasi ditunjukkan pada Gambar 1.
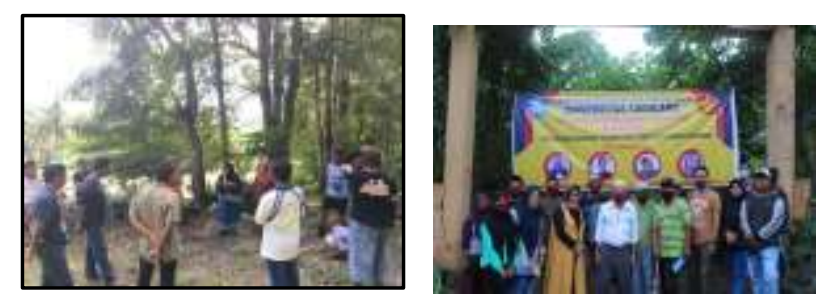

Gambar 1. Kunjungan ke kebun konservasi Asyifa'a

\subsection{Penyuluhan dan pelatihan teknik konservasi tumbuhan obat}

Penyuluhan dan pelatihan teknik konservasi tumbuhan obat (TO) dilaksanakan di areal kebun konservasi dengan tujuan untuk memudahkan peserta dalam melakukan konservasi karena dapat melihat langsung jenis tumbuhan obat dan karakteristik morfologinya dan teknik mengembangkan tumbuhan obat tersebut (Donaldson, 2009). Selain itu juga bertujuan untuk meningkatkan kesadaran dan semangat dalam mengembangkan pemanfaatan tumbuhan obat secara mandiri (Amzu et al., 2007). Penyuluhan dan 
pelatihan tersebut juga melibatkan anggota kedua kelompok masyarakat mitra PPDM dan dilaksanakan selama 3 hari. Materi pelatihan yang diberikan adalah: Teknik persemaian dan pembibitan tumbuhan obat, teknik budidaya berbagai jenis tumbuhan obat, teknik pengembangan pupuk organik, dan penanganan hasil dan pemasaran tumbuhan obat.

Selama pelaksanaan pelatihan teknik konservasi, narasumber menyampaikan materi terlebih dahulu kemudian dilanjutkan dengan tanya jawab dan diskusi serta selanjutnya dilakukan praktek dan demplot teknologi. Penyampaian materi pelatihan dan suasana saat pelatihan seperti ditunjukkan pada Gambar 2.
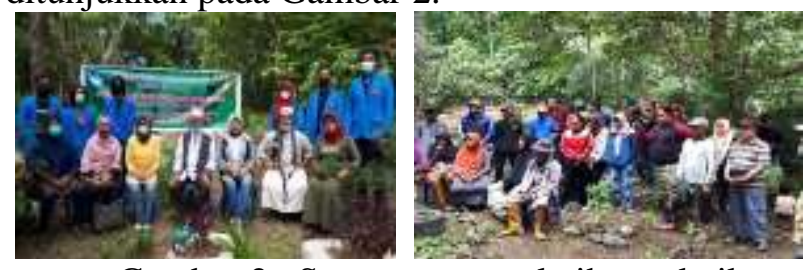

Gambar 2. Suasana saat pelatihan teknik konservasi tumbuhan obat

\subsection{Demonstrasi praktik langsung}

Kegiatan alih teknologi berupa demonstrasi praktik langsung budidaya tumbuhan obat di areal konservasi meliputi penyiapan media tanam, penanaman bibit dan pemeliharaan tanaman. Bibit tumbuhan obat ditanam di polybag menggunakan media tanam seperti pada budidaya tanaman sayuran umumnya yang ditanam di lahan pekarangan yaitu tanah, arang sekam, dan kompos (Lasmini et al., 2020) dengan perbandingan 1:1:1. (Gambar 3). Selanjutnya setelah tumbuh kuat, dipindahkan ke pertanaman yang sudah dipersiapkan sebelumnya (Gambar 4).
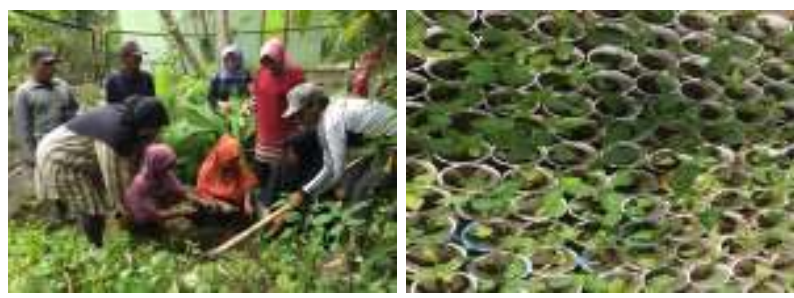

Gambar 3. Pengisian polibag oleh peserta dengan dipandu oleh tim pelaksana

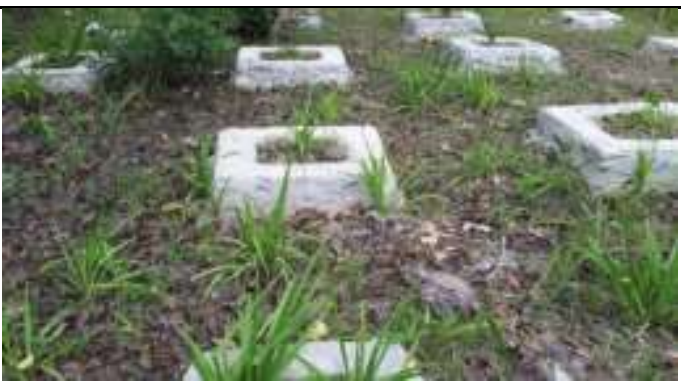

Gambar 4. Bibit tumbuhan obat yang sudah tumbuh di areal pertanaman

\subsection{Penanaman tumbuhan obat di halaman pekarangan masyarakat}

Pemanfaatan lahan pekarangan terutama bagi anggota mitra program desa mitra ini bertujuan untuk memberi motivasi kepada masyarakat dalam memanfaatkan lahan pekarangan dengan menanam tumbuhan obat yang bertujuan untuk mendekatkan tumbuhan obat dengan masyarakat. Penanaman tumbuhan obat pada lahan pekarangan tidak saja ditekankan pada aspek budidaya, tetapi juga menekankan pada aspek keasrian pekarangan. Sebanyak 10 rumah warga yang terdaftar sebagai mitra ditetapkan sebagai demplot percontohan budidaya tumbuhan obat di halaman pekarangan, dengan jenis yang dikembangkan adalah yang bernilai ekonomi dan berjangka panjang.

Tumbuhan obat yang dibudidayakan di halaman pekarangan sebenarnya tidak membutuhkan pemeliharaan khusus, kecuali untuk skala usaha yang bertujuan untuk memperoleh kualitas dan kuantitas, serta keuntungan maksimum. Budidaya tumbuhan obat di pekarangan membutuhkan perawatan seperti pemupukan, penyiraman, penyiangan gulma, pembumbunan, dan pengendalian hama penyakit (Gambar 5).
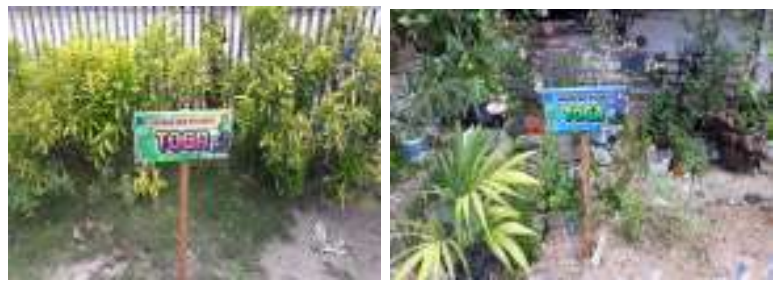

Gambar 5. Lahan pekarangan yang telah difungsikan dengan penanaman $\mathrm{TO}$ 
Pembudidayaan tumbuhan obat di halaman pekarangan memberi keuntungan bagi masyarakat antara lain efektif jika dibutuhkan segera, memberikan kesan asri pada halaman rumah karena rata-rata tanaman obat bewarna hijau, serta dapat meningkatkan pendapatan masyarakat. Selain itu juga digunakan sebagai edukasi tanaman herbal atau tanaman obat tradisional kepada anggota keluarga, dikonsumsi sebagai tindakan menjaga kesehatan tubuh dan salah satu tindakan nyata penghijauan tanaman (Dewi \& Widiyawati, 2019).

\section{KESIMPULAN}

Pelaksanaan pelatihan teknik konservasi tumbuhan obat untuk mendukung progam penyediaan obat herbal di Sulawesi Tengah kepada masyarakat di Desa Pakuli Kecamatan Gumbasa berlangsung dengan baik dan dapat diadopsi oleh masyarakat yang diindikasikan dengan kegiatan penanaman tumbuhan obat oleh masyarakat di halaman pekarangan rumah masing-masing.

Pelaksanaan penyuluhan yang diikuti sebanyak 35 orang peserta dari 2 kelompok mitra kegiatan dapat meningkatkan pengetahuan masyarakat yang ditandai dengan meningkatnya ketrampilan pada saat praktek budidaya tumbuhan obat, baik yang dilaksanakan di areal konservasi maupun di lahan pekarangan.

Dengan konservasi tumbuhan obat terutama yang tergolong langka, maka masyarakat dapat mendekatkan diri dengan tumbuhan obat langka tersebut untuk kepentingan penyediaan obat herbal bagi anggota keluarganya.

\section{UCAPAN TERIMA KASIH}

Program PPDM ini dibiayai oleh Direktorat Riset dan Pengabdian Kepada Masyarakat Direktorat Jenderal Penguatan Riset dan Pengembangan Kementerian Riset, Teknologi dan Pendidikan Tinggi, Sesuai dengan Perjanjian Penugasan Pelaksanaan Program Pengabdian Masyarakat Nomor: 078/SP2H/PPM/DRPM/2021

\section{REFERENSI}

Amzu, E, Sofyan, K., Prasetyo, L.B., \& Kartodihardjo, H. (2007). Sikap masyarakat dan konservasi: suatu analisis kedawung (Parkia timoriana (DC) Merr.) sebagai stimulus tumbuhan obat bagi masyarakat, Kasus di Taman Nasional Meru Betiri. Media Konservasi XII, 22 - 32.

BPS Kabupaten Sigi (2017), Letak dan jarak antar desa dan kecamatan di Kecamatan Gumbasa. BPS Kabupaten Sigi.

Dewi, P.S., \& Widiyawati, I. (2019). Pengenalan teknologi budidaya tanaman obat sebagai upaya pemanfaatan lahan pekarangan di Kelurahan Pabuwaran Purwokerto, Jawa Tengah. Panrita Abdi 3 (2). 105-112. http://journal.unhas.ac.id/index.php/panritaab di

Donaldson, J.S. (2009). Botanic gardens science for conservation and global change. special issue: Plant science research in botanic gardens. Trends in Plant Science 14 (11): 608-613. Elsevier Ltd. All rights reserved. doi:10.1016/j.tplants.2009.08.008.

Hikmat, A., Zuhud, E.A.M., Siswoyo, Sandra, E., \& Sari, R.K. (2011). Revitalisasi konservasi tumbuhan obat keluarga (TOGA) guna meningkatkan kesehatan dan ekonomi keluarga mandiri di desa contoh lingkar kampus IPB Darmaga Bogor. Jurnal Ilmu Pertanian Indonesia, 16 (2): 71-80.

Irwanta, E., Hikmat, A., \& Zuhud, E.A.M. (2015). Keanekaragaman simplisia nabati dan produk obat tradisional yang diperdagangkan di Kabupaten Pati, Jawa Tengah. Media Konservasi 20 (3): 197 - 204

Lasmini, S.A., Monde, A., Tarsono, Idham, \& Nasir, B. (2020). Bimbingan teknik budidaya sayuran organik untuk Menghasilkan sayuran sehat dan bebas residu bahan kimia. JMM (Jurnal Masyarakat Mandiri) 4 (4), 623-632 https://doi.org/10.31764/jmm.v4i4.2603

Noorhidayah, Sidiyasa, K., \& Hajar, I. (2006). Potensi dan keragaman tumbuhan obat di hutan Kalimantan dan upaya konservasinya, Jurnal Analisis Kebijakan Kehutanan Kehutanan, 3(2): 96-107. 
Parwata, I.M.O. (2016). Obat Tradisional. Diktat. Jurusan Kimia. Laboratorium Kimia Organik Fmipa Universitas Udayana

Rosmini, Ete, A., Edy, N., Nasir, B., \& Wulandari, D.R. (2020). Teknik konservasi tumbuhan obat untuk mendukung program penyediaan obat herbal di Sulawesi Tengah. Prosiding Seminar Nasional Pertanian VII: Pola Pertanian Lahan Kering Berkelanjutan, 230236.

Rosmini, Lasmini, S.A., Ete, A., Wulandari, D.E., Edy, E., Hayati, N., \& Taeyeb, A. (2021). Bimbingan teknik budidaya tumbuhan obat untuk penyediaan simplisia obat herbal bagi masyarakat. DINAMISIA: Jurnal Pengabdian Kepada Masyarakat 5,(2): 294299.

DOI:
Sebayang, H.T. Yurlisa, K., Widaryanto, E., \& Aini, N. (2020). Penerapan teknologi budidaya tanaman jahe di pekarangan berbasis pertanian sehat di Desa Bokor, Kabupaten Malang. Jurnal Pengabdian Pada Masyarakat, $5(1), \quad 45-50 . \quad$ DOI: 10.30653/002.202051.254

Tudjuka, K., Ningsih, S., \& Toknok, B. (2014). Keanekaragaman jenis tumbuhan obat pada kawasan hutan lindung di Desa Tindoli Kecamatan Pamona Tenggara Kabupaten Poso. Warta Rimba 2 (1): 120-128

Zuhud, (2015). Potensi hutan tropika Indonesia sebagai penyangga bahan obat alam untuk kesehatan bangsa.

https://doi.org/10.31849/dinamisia.v5i2.4641 